\title{
Currículo, narrativas digitais e formação de professores: Experiências da pós-graduação à escola
}

\author{
Alessandra Rodrigues ${ }^{i}$ \\ Universidade Federal de Itajubá, Brasil \\ Maria Elizabeth Bianconcini de Almeidaii \\ Pontifícia Universidade Católica de São Paulo, Brasil \\ José Armando Valenteiii \\ Universidade Estadual de Campinas, Brasil
}

Resumo

A formação de educadores para a integração das tecnologias ao currículo em diferentes contextos educacionais foi o foco deste estudo, que teve como objetivo entender como o desenvolvimento de narrativas digitais contribuiu para essa formação. Os educadores investigados eram mestrandos de um Programa de Pós-Graduação em Ensino de Ciências de uma universidade pública brasileira que atuavam também como professores em diversos níveis de ensino. A estratégia de aprendizagem foi baseada no desenvolvimento de narrativas digitais. Os dados desta investigação foram coletados por meio de questionário eletrônico aplicado aos sujeitos. Os resultados da pesquisa indicam: a) mudanças na maneira como os mestrandos passaram a entender a prática pedagógica que desenvolvem; b) aprendizagens relacionadas com a produção de narrativas digitais e com sua aplicação recontextualizada em diferentes disciplinas ministradas pelos mestrandos; c) percepção, pelos sujeitos, do potencial educacional das narrativas digitais.

Palavras-chave

Tecnologias educacionais; Aprendizagem; Prática pedagógica; Ensino de Ciências 


\section{Introdução}

A elaboração de narrativas tem sido utilizada de longa data como instrumento de pesquisa e em processos educativos para a construção, desconstrução (Cunha, 1997) e reconstrução das experiências. Quando se trata da elaboração de narrativas digitais, isto é, das narrativas que utilizam as tecnologias digitais de informação e comunicação (TDIC) como instrumentos de representação dos processos de aprendizagem e das produções dos alunos, como enfatizado no presente estudo, as tecnologias trazem contribuições peculiares. Isso é possível graças às suas propriedades constitutivas, que propiciam a representação do pensamento, a reflexão sobre o representado, a reformulação das ideias, a partilha e a colaboração, assumindo o papel de espelhos da mente do aluno (Almeida \& Valente, 2012).

As narrativas produzidas pelos alunos propiciam a reelaboração do currículo na prática social educativa (Almeida \& Valente, 2012) em diálogo com os pares e formadores, a construção de narrativas curriculares singulares (Goodson, 1997) em uma perspectiva transformadora (Freire, 1987). Tais produções têm sido objeto de estudos com distintos enfoques, como o estudo de contextos de aprendizagem por meio de tecnologias digitais (Valente \& Almeida, 2014), a integração entre currículo e contextos de aprendizagem formal e não-formal (Almeida \& Valente, 2012). As experiências de produção de narrativas digitais podem ser recontextualizadas por docentes e discentes, que as utilizam em outros espaços educativos, como é o caso de que tratamos neste artigo, em que as experiências realizadas por meio da produção de narrativas digitais em uma disciplina presencial de um programa de mestrado profissional em Ensino de Ciências de uma instituição pública brasileira reverberaram na educação básica por meio de professores/alunos do mestrado profissional.

A utilização das narrativas digitais em distintas esferas da formação de educadores pode ser compreendida pelo entrelaçado da rede teórica e metodológica, que fundamenta as concepções, as práticas e os processos de investigação, conforme tratamos neste texto, com o objetivo de discutir o desenvolvimento das narrativas digitais como estratégia de aprendizagem que potencializa a transformação do aluno e, na formação de professores, instiga alterações na prática pedagógica. 


\section{Narrativas digitais e formação docente}

O estudo de narrativas não é novo nas diversas áreas das Ciências Humanas e apresenta variados enfoques (Galvão, 2005; Gonçalves \& Fernandes, 2010). Mais recentemente, as narrativas digitais de aprendizagem vêm se configurando como um interessante objeto de estudo na área da Educação e seu uso tem protagonizado algumas experiências significativas também na formação de professores, embora essa temática específica ainda seja incipiente nas publicações encontradas em bancos de dados brasileiros, como o Portal de Periódicos e o Banco de Teses e Dissertações da CAPES (Coordenação de Aperfeiçoamento de Pessoal de Nível Superior).

Na formação de professores, inicial ou continuada, o uso de narrativas digitais de aprendizagem pode contribuir para a integração entre as TDIC e os currículos e promover práticas pedagógicas mais autorais (Bottentuit Junior, Lisbôa, \& Coutinho, 2012; Coutinho, 2010), abrindo caminho na contramão de um cenário educacional de uso excessivo de material apostilado, currículo prescrito com ênfase em listas de conteúdos e voltado mais às avaliações e ranqueamentos do que ao processo formativo, entre outros fatores, que têm tornado os professores da educação básica cada vez mais "tarefeiros" com vistas ao cumprimento das atividades curriculares prescritas.

Dados do Instituto Nacional de Estudos e Pesquisas Educacionais Anísio Teixeira - INEP (2013) mostram que, em 2012, 78,1\% dos professores atuantes do ensino fundamental e médio no Brasil tinham nível de educação superior concluído. No entanto, o grau de formação não vem garantindo práticas docentes emancipatórias nas escolas. Gatti (2010) nos apresenta informações que podem ser indicativos para explicar essa situação: os recursos didáticos mais utilizados nos cursos de licenciatura são apostilas, resumos e cópias de trechos de textos (63\%). Ou seja, o professor é preparado pela repetição, pelo apostilamento e pela cópia. Como, então, poderá preparar seus alunos de maneira diferente, com práticas promotoras de autoria, posicionamento crítico e empoderamento dos sujeitos?

Uma formação que contribua para romper essa lógica precisa considerar que o currículo não pode ser desvinculado do contexto em que se insere nem das condições em que se desenvolve; sendo, portanto, um objeto histórico e social (Gimeno Sacristán, 2000). Nesse viés, protagonismo e 
autoria são elementos-chave que vêm sendo desconsiderados em grande parte dos cursos de formação, como aponta Arroyo (2013) ao afirmar que "a indiferença com o autor, com os sujeitos é uma característica dos currículos. Os sujeitos desaparecem, não têm espaço como sujeitos de experiências, de conhecimentos, de pensares, valores e culturas" (p. 53).

Compreendendo o currículo como uma construção social cujo desenvolvimento parte da experiência do aluno, mas não se restringe a ela (Almeida \& Silva, 2011), não podemos desconsiderar o potencial educacional das narrativas de aprendizagem bem como sua importância na construção do currículo real, experienciado, vivenciado nas situações de ensino e aprendizagem, uma vez que envolvem "o saber, a identidade e a racionalidade sobre como as pessoas constroem o conhecimento do mundo ao seu redor, a compreensão de si mesmas e a interlocução com as outras pessoas" (Almeida \& Valente, 2012, p. 63).

Vistas por uma perspectiva ampla, as narrativas são uma forma de contar, uma maneira de lembrar, um jeito de registrar as memórias, reviver as histórias e (re)significar o vivido. A narrativa pode realizar-se em suportes expressivos variados e não se concretiza somente no plano estético-literário, mas também em contextos funcionais de comunicação (Costa, 2009); por isso, em contextos de aprendizagem é uma possibilidade rica de construção de conhecimentos.

$\mathrm{O}$ ato de usar a narrativa como recurso pedagógico reconhece a aprendizagem como processo e coloca em foco a experiência pessoal de aprender favorecendo o protagonismo e a autoria do aprendente, que, para a construção de sua narrativa, seleciona aquilo que o atravessou, tombou, desestabilizou durante a aprendizagem, para refletir, avançar e criar suas produções. Temos aí o sentido larrosiano de experiência como "o que nos passa, o que nos acontece, o que nos toca. Não o que se passa, o que acontece, ou o que toca" (Larrosa, 2002, p. 21; sublinhado nosso).

Em outras palavras, o exercício de narrar o processo de aprendizagem e narrar-se por esse processo leva o sujeito a estabelecer diferenças entre 0 que aconteceu e o que the aconteceu. Durante ações de ensinar e aprender muitas coisas acontecem, mas às vezes poucas coisas ou nenhuma acontece ao sujeito no sentido de fazê-lo viver uma experiência de aprendizagem autêntica. Ao produzir uma narrativa desse processo, é preciso fazer 
escolhas, ser crítico, analisar, atribuir sentidos e eleger o que foi, de fato, uma experiência. Nesse sentido, a narrativa ajuda a estabelecer mais claramente a relação entre subjetividade e objetividade, tão importante na construção do conhecimento.

Assim, ao ordenar suas experiências de aprendizagem em um todo significativo por meio da narrativa, o sujeito instaura um movimento de conhecimento e autorreconhecimento. Coloca-se como parte ativa do processo de aprendizagem, conscientiza-se das experiências que teve, dos avanços que fez, e atribui significados às informações advindas dessas experiências no exercício de representar seu pensamento e desenvolver produções que tendem a ter um caráter mais autoral.

As narrativas funcionam, dessa forma, como janelas que se abrem para a mente dos alunos, permitindo ao professor compreender o processo individual de cada sujeito em relação à construção do conhecimento. Além do que, oportunizam "a tomada de consciência sobre a própria aprendizagem e transformação" (Almeida \& Valente, 2012, p. 62), uma vez que ao narrar os seus percursos e desenvolver suas produções, os sujeitos desempenham o papel de atores e de investigadores de suas próprias vidas.

Tendo os suportes mais diversos, as narrativas digitais são terrenos férteis de investigação, pois a textualidade eletrônica é multimidiática

na medida em que é semioticamente híbrica, englobando o texto escrito, a exploração de suas possibilidades gráficas, as distintas mídias imagéticas (gráficas, fotográficas e videográficas) e o som. ... Aí está um dos poderes mais significativos da escrita na nova mídia: reunir o texto com a imagem, assim como com outras mídias. (Santaella, 2007, p. 335)

As narrativas digitais trazem, dessa forma, além do discurso escrito de seu autor, outros elementos (típicos das TDIC) capazes de colocá-lo no mundo e ajudá-lo a contar suas histórias com o uso de múltiplas linguagens. Além disso, a narrativa digital pode ser continuada, compartilhada, comentada, reelaborada a qualquer tempo e de qualquer lugar (se pensarmos na possibilidade de armazenamento em nuvens, por exemplo) - o que lhe confere grande dinamicidade e amplia sobremaneira suas possibilidades pedagógicas. Assim, a incorporação das narrativas digitais às práticas curriculares na formação docente implementa um processo formativo orientado pelas premissas de integração entre tecnologia-currículo- 
sociedade, na medida em que viabiliza que os conhecimentos técnicos/tecnológicos aliem-se aos conhecimentos pedagógicos e sejam costurados pela via da narrativa (Coutinho, 2010; Galvão, 2005; Jesus, 2010; Robin, 2008).

Apoiados nas ideias de Bruner (1991), entendemos que a narrativa representa as ações, intenções e significados atribuídos pelo autor no âmbito de determinado contexto, em interação com os pares e com os instrumentos da cultura. No entanto, a narrativa digital aporta outras características próprias das tecnologias digitais, com destaque para a diacronicidade narrativa devido à flexibilidade de espaço e tempo, a representação do pensamento por meio de hipermídias multimodais, o fazer e o refazer contínuos.

Se a educação está hoje inserida num mundo de cultura digital, a profissionalidade docente está também mergulhada nas conexões, multimodalidades e hipermodalidades propiciadas pelas TDIC. No espaço/tempo da cultura digital em que vivemos, torna-se essencial que os professores também se apropriem das TDIC em experiências autênticas, tanto no próprio processo de aprendizagem quanto em sua prática pedagógica.

$\mathrm{Na}$ formação docente, narrar o próprio processo de aprendizagem possibilita que o professor experimente o papel de um "aluno-protagonista", cuja trajetória de aprendizagem é reconhecida e valorizada por meio da elaboração de sua narrativa. Assim, as narrativas digitais conferem um ganho potencial às práticas pedagógicas nos cursos de formação de professores e a possibilidade, a partir daí, de se tornarem uma prática também nas escolas, conforme a experiência que discutiremos a seguir.

\section{Abordagem metodológica}

Neste tópico apresentamos os aspectos metodológicos da investigação, que tem abordagem qualitativa em relação ao planejamento, ao tratamento e à análise dos dados (Bogdan \& Biklen, 1999; Denzin \& Lincoln, 2006). Admitindo que a realidade é fluente e contraditória, esse tipo de investigação pode associar grande variedade de instrumentos e técnicas como modos de abordar e compreender essa realidade (Chizzotti, 2011). 


\subsection{Contexto e sujeitos da investigação}

Este estudo foi desenvolvido em um Programa de Pós-Graduação em Ensino de Ciências - Mestrado Profissional de uma universidade federal brasileira. O contexto de produção e socialização de narrativas digitais foi uma disciplina obrigatória na estrutura curricular do curso, com carga horária de 60 horas-aula semestrais, sendo oferecida na modalidade blended learning, com 20 horas presenciais e 40 horas desenvolvidas por meio de atividades virtuais.

Os dezasseis mestrandos que cursaram a disciplina no segundo semestre de 2014 foram os sujeitos desta investigação. Em sua maioria eram professores da Educação Básica, mas alguns já atuavam como docentes no Ensino Superior. Para familiarizar esses sujeitos com a proposta de produzir narrativas digitais durante a disciplina do Mestrado, foram apresentadas narrativas digitais produzidas por uma das pesquisadoras. Essas narrativas traziam o processo de formação da pesquisadora no doutorado permeado pelas incertezas, inconstâncias, descobertas e expectativas que fazem parte da investigação científica, mas com o olhar subjetivo e a construção individual da autora.

Também foram apresentados aos mestrandos recursos digitais que poderiam servir de suportes às narrativas, desde os já conhecidos editores de textos e slides até programas de edição de sites, vídeos, e-books e animações - esses últimos desconhecidos da maior parte dos sujeitos. Cada mestrando escolheu o suporte no qual desenvolveria sua narrativa digital.

As narrativas digitais dos mestrandos foram produzidas ao longo de todo o semestre letivo e socializadas no ambiente virtual utilizado na disciplina. A cada postagem de versões parciais dessas narrativas, todo o grupo também registrava comentários nesse ambiente. A proposta de produção de narrativas digitais restringia-se às atividades de uma disciplina do Mestrado, mas extrapolou rapidamente o contexto desse curso e chegou às salas de aula onde os sujeitos atuavam como docentes. Dos dezesseis mestrandos pesquisados, treze estavam atuando em sala de aula. E seis desses treze mestrandos implementaram, de alguma maneira, a produção de narrativas como uma prática pedagógica ainda durante o semestre em que produziram suas próprias narrativas digitais no Mestrado. 
Esse fato instigou a realização desta investigação e, por si, já nos ajuda a perceber a importância de, ao articular as TDIC ao currículo da formação de professores, "criar condições para que os educadores compreendam a tecnologia em seus 'modos de produção de forma a incorporá-la na prática'" (Almeida \& Valente, 2011, p. 32). O que corrobora as afirmações de Vieira Pinto (2005), quando este aponta para a necessidade de se pensar socialmente a tecnologia.

Nesse sentido, as narrativas digitais produzidas pelos mestrandos que se constituem como sujeitos deste estudo foram utilizadas como: a) objeto de investigação, conforme já enfatizado neste artigo; b) estratégia de formação segundo a abordagem emancipatória (Cunha, 1997) com a elaboração das narrativas que integram linguagens, TDIC e sistemas multimodais para a representação do conhecimento e a escolha de caminhos a seguir, revelandose como "espelho da mente" dos mestrandos (Almeida \& Valente, 2012); c) instrumento de aprendizagem que permitia ao mestrando refletir sobre seu desenvolvimento e fazer as autorregulações no processo de reconstrução e desconstrução das experiências.

\subsection{Instrumentos de coleta de dados e orientações de análise}

Após a finalização da experiência realizada na disciplina, o questionário foi considerado $o$ instrumento de coleta de dados mais adequado, uma vez que permite aplicação rápida e simultânea para todos os mestrandos, além de não exigir identificação por parte desses sujeitos - o que poderia resultar em respostas mais sinceras. Assim, optamos pela aplicação de questionário virtual, aberto, cujas perguntas foram elaboradas em consonância com o objetivo deste estudo, já apresentado na Introdução, com a intenção de saber: a) que contribuições a produção de narrativas digitais trouxe ao processo de aprendizagem desses sujeitos; b) se eles haviam percebido perspectivas de utilização das narrativas com seus alunos e; c) caso já tivessem utilizado as narrativas digitais, que contribuições essa experiência trouxe para sua prática pedagógica. $O$ instrumento passou por processo de validação interna dos pesquisadores, por meio de leitura e depuração das questões propostas. 
Dos dezasseis sujeitos que receberam o questionário, dez responderam ao instrumento. Após uma primeira leitura das respostas, quatro grandes temáticas emergiram dos dados: aprendizagem do professor, transformação profissional, potencial das narrativas digitais e prática pedagógica. A partir dessas temáticas, foram criadas macrocategorias de análise. Os dados foram analisados qualitativamente e o software NVivo (que permite organizar e analisar conteúdos diversos, dentre os quais mídias sociais e páginas web) foi utilizado para auxiliar a organização dos excertos nas temáticas.

A primeira ação no software foi incluir os arquivos com as respostas dos sujeitos para, em seguida, criar os "nós" referentes a cada temática ou macrocategoria de análise identificada pela leitura inicial das respostas. A ação seguinte foi a atribuição dos excertos de respostas aos respectivos nós. Após essa categorização dos dados tivemos 35 ocorrências atribuídas às quatro macrocategorias, distribuídas da seguinte forma: 12 excertos atribuídos à "Prática pedagógica"; 12 trechos vinculados à "Transformação profissional"; 8 referências à "Aprendizagem do professor"; e 6 respostas diretamente ligadas ao "Potencial das narrativas digitais". Esse material compõe, assim, nosso corpus de análise. Para preservar a identidade dos sujeitos de pesquisa, os mestrandos serão identificados como M1, M2, M3, e assim sucessivamente.

Em decorrência da extensão do material gerado e analisado, optamos por apresentar os resultados deste estudo associados à discussão e análise.

\section{Resultados e discussão: Narrativas digitais, aprendizagem e transformação da prática pedagógica}

Neste tópico apresentaremos conjuntamente os resultados do estudo e as discussões elaboradas a partir das análises referentes a cada uma das macrocategorias mencionadas na abordagem metodológica.

\subsection{Prática pedagógica}

A primeira macrocategoria diz respeito às mudanças na prática pedagógica dos mestrandos a partir do contato, na pós-graduação, com as narrativas digitais. Salientamos que essa macrocategoria apresentou grande 
número de ocorrências, o que pode ser explicado pelo fato de seis dos dez mestrandos respondentes terem utilizado as narrativas como recurso didático e cinco deles terem feito referência direta a essa prática no questionário, conforme apresentamos nos excertos a seguir.

Chama atenção a variedade de níveis de ensino em que atuam os mestrandos que implementaram a produção das narrativas digitais em suas turmas: M1 atua no Ensino Fundamental I, M2 leciona em cursos técnicos, M3 utilizou as narrativas digitais na formação de professores do Ensino Superior, M4 o fez no Ensino Fundamental Il e no Ensino Médio, e M5 no curso superior de Medicina:

Resolvi trabalhar dentro do projeto de Educação Financeira, com meus alunos do quinto ano. (M1)

Solicitei a eles a elaboração de uma narrativa vinculada com a disciplina que leciono. ... A experiência foi a melhor possível, e pretendo repetir esta didática de descrição de pensamentos, falas, conceitos e reflexões com outras turmas do curso técnico em enfermagem e segurança do trabalho. (M2)

Eu estou usando a minha narrativa num encontro que estamos fazendo entre professores da faculdade onde trabalho. $\mathrm{O}$ intuito dos encontros é conhecer $\mathrm{O}$ trabalho dos colegas e discutir dificuldades encontradas em sala de aula, bem como propor práticas para solucioná-las. Para isso cada professor está montando sua narrativa, seguindo o exemplo da minha. (M3)

Este ano, estou lecionando em um terceiro ano do ensino médio e, no começo do ano, expliquei a eles a importância da narrativa. Sempre que fazemos uma atividade em grupos, eles já me perguntam: 'A narrativa é para a próxima aula?'. (M4)

Passei a pensar em coisas que no dia a dia vão se tornado automáticas e envolvi meus alunos nessa reflexão. Compartilhei com eles as dificuldades da nossa prática e estimulei que eles buscassem prováveis soluções para tais dificuldades. (M5)

Os depoimentos ratificam as múltiplas possibilidades de utilização das narrativas digitais e sua versatilidade como estratégia de aprendizagem em distintos níveis de formação. Além disso, confirmam a ideia de que formar professores para integrar as tecnologias ao currículo vai muito além de desenvolver as capacidades técnicas desses sujeitos em relação às tecnologias. É preciso criar condições para que o professor compreenda as TDIC como algo mais amplo do que ferramentas para agilizar a realização de 
tarefas, ressignifique seu uso no contexto escolar e as utilize para "o desenvolvimento da capacidade de dialogar, representar o pensamento, buscar, selecionar e recuperar informações, construir conhecimento em colaboração" (Almeida \& Valente, 2011, p. 31).

Alguns reflexos da utilização das narrativas digitais também foram narrados pelos mestrandos. Os reflexos percebidos em seus alunos nos indicam elementos importantes que fazem parte de questões problemáticas frequentemente abordadas nas discussões sobre educação. O primeiro é a falta de motivação e interesse dos estudantes. Os depoimentos fazem referência a um aumento na motivação, participação e interesse dos alunos: "Os alunos adoraram trabalhar com recursos digitais nas nossas aulas, algo presente no cotidiano deles" (M1); "Percebi uma melhora na minha relação com eles e na motivação destes para assistir minha aula" (M5).

Outros reflexos mostram ganhos do ponto de vista da aprendizagem de recursos digitais e dos conteúdos curriculares, além do desenvolvimento da capacidade de reflexão e crítica dos estudantes:

... com isso alguns aprenderam a utilizar recursos que não sabiam. (M1)

Obtive resultados que demonstraram que a capacidade deles é aumentada, quando o professor estimula-os a fazer algo diferente. (M2)

A narrativa conseguiu virar hábito na minha prática docente. Um hábito saudável tanto para mim quanto para meus alunos. No começo, suas escritas eram somente sobre o trabalho. Não havia reflexões sobre como o trabalho fora desenvolvido. Hoje eles já conseguem apontar erros e acertos nos trabalhos apresentados por outras equipes, o que eu acho muito interessante. (M4)

... neles [os alunos] acredito que tenha estimulado também uma postura mais reflexiva que poderá ser levada para sua vida profissional. (M5)

Todos esses ganhos corroboram a ideia de Bottentuit Junior et al. (2012) de que a construção de narrativas digitais é "uma experiência que poderá levar os alunos a realizarem aprendizagens mais significativas, ... e ainda por cima eles aprendem a trabalhar com ferramentas tecnológicas que podem ser úteis também em outros contextos e disciplinas curriculares" (p. 194).

Neste tópico de análise foram apresentados elementos que indicam a relevância da utilização das narrativas digitais na formação de professores e seus efeitos positivos sobre a prática pedagógica dos docentes. Ressaltamos 
neste tópico: a) a ressignificação/recontextualização do uso da narrativa feita pelos mestrandos em sua prática como docentes; b) indícios de aumento da motivação docente para se engajar na produção das narrativas digitais; c) indícios de apropriação de recursos digitais em situações didáticas e fora delas; d) o estímulo oferecido pela produção de narrativas digitais em relação à reflexão sobre a ação docente.

\subsection{Transformação profissional}

A macrocategoria "Transformação profissional" está intimamente ligada à macrocategoria anterior (Prática Pedagógica), o que poderia explicar o número de ocorrências para esta temática, uma vez que a mudança na prática docente gera uma transformação do profissional professor e viceversa. Alguns aspectos se destacam nos depoimentos desta macrocategoria: o primeiro que queremos apontar é o movimento, desencadeado pelas narrativas, de reflexão do professor-mestrando sobre sua prática e um compromisso com a melhoria dessa prática em prol dos alunos, de registrar a própria prática e de revisitar os registros:

O uso das narrativas digitais me proporcionou uma reflexão da minha prática. Aprendi a parar e refletir mais a fundo as minhas ações, o que me motivava a querer buscar fazer sempre mais com meus alunos. (M1)

O ato de narrar nos faz pensar a nossa prática, é um lembrar e relembrar das nossas atitudes em sala de aula, me fez traçar uma linha de evolução nas minhas aulas, pois pude perceber que aos poucos fui crescendo em dinamismo e versatilidade, e isso, por consequência, faz com que eu queira ser melhor ainda para meus alunos. (M2)

As narrativas digitais me fizeram refletir sobre minha prática pedagógica, pensar e repensar os meus passos, me fizeram questionar minhas atitudes dentro de sala de aula e torná-las melhores, aperfeiçoar. (M8)

Em mim mudou a necessidade de sempre reler aquilo que faço. Entendi que o verdadeiro aprendizado acontece se estamos de fato envolvidos e que escrever sobre a prática nos faz enxergar detalhes tão simples e ao mesmo tempo tão preciosos. (M5)

A confecção das narrativas me fez refletir sobre cada aula e cada experiência de uma forma diferente. Muitas vezes as situações rotineiras passavam e depois, ao narrar, eu podia perceber coisas que antes não havia notado e enxergar de outra a forma. (M10) 
Os depoimentos revelam que as narrativas geram a objetivação do pensamento por meio da linguagem e esse processo tem um efeito reverso sobre a atividade mental do sujeito, conforme propõem autores como Vygotsky $(1989,2000)$ e Bakhtin $(1992,2009)$. Em outras palavras, narrar leva à conscientização sobre a experiência vivida, à sua reflexão e à ressignificação da experiência e do próprio sujeito nesse processo. Como aponta Passeggi (2011), "Ao narrar sua própria história, a pessoa procura dar sentido às suas experiências e, nesse percurso, constrói outra representação de si: reinventa-se" (p. 147).

Outro aspecto ligado à transformação na postura profissional dos sujeitos diz respeito à ampliação do envolvimento desses com seus alunos, como podemos perceber pelos depoimentos seguintes:

O envolvimento com os meus alunos foi uma grande contribuição, como professora. ...pensando em mim como educadora, me envolvi mais com eles, no sentido da instrução, da leitura minuciosa dos textos, e nas correções do português. (M6)

Percebi uma melhora na minha relação com eles. (M5)

No relato de M4 percebemos outra transformação importante provocada pela inclusão das narrativas em sua prática pedagógica: a postura de um professor mais aberto ao novo, ao que ele não domina completamente e que o coloca também numa posição de aprendiz:

Apesar de lecionar Matemática, aprendi a pedir aos alunos que escrevessem uma narrativa sobre uma atividade diferente que fosse praticada em sala de aula. No começo, os alunos estranharam e me perguntavam: 'É aula de Português ou de Matemática?'. Pra mim também era novidade, pois tendo trabalhado por quase trinta anos e nunca tinha registrado nada, além das fotos. (M4)

A mudança de atitude do professor em relação a uma experiência nova nos ajuda a pensar sobre a questão das TDIC em sala de aula. Como apontam Almeida e Valente (2011), a integração das tecnologias ao currículo escolar não pode se dar de cima para baixo, por decreto, nem é um processo que se reduz ao domínio dos recursos tecnológicos. Ao contrário, é um processo de "mudança de atitude e de práticas educacionais com o envolvimento de alunos e professores em processos de aprendizagem e ensino, nos quais se tornam aprendizes e ensinantes, todos aprendem juntos e em comunhão" (Almeida \& Valente, 2011, p. 45). 
Neste item de análise, destacamos como aspectos relevantes oriundos das respostas ao questionário: a) depoimentos sobre a mudança da prática promovida pela reflexão sobre o registro feito nas narrativas digitais; b) a conscientização e ressignificação da experiência por meio da objetivação do pensamento materializado nas narrativas digitais dos discentes; c) o envolvimento dos docentes (mestrandos) com seus alunos; d) a mudança de postura dos professores-mestrandos em relação ao novo, assumindo uma posição de aprendizes.

\subsection{Aprendizagem do professor}

A postura de professor-aprendiz observada anteriormente está ligada à nossa próxima macrocategoria de análise, "Aprendizagem do professor", e aparece ilustrada em vários depoimentos. As aprendizagens descritas pelos mestrandos voltam-se: a) ao uso da tecnologia, b) aos conteúdos curriculares da disciplina do mestrado, e c) à própria postura dos sujeitos em relação à sua atividade profissional.

A aprendizagem tecnológica está relatada nos depoimentos a seguir:

Além disso, aprendi a usar recursos digitais que nunca havia usado, como blog, prezzi e o site. (M1)

Me assustei (sic) quando comecei a elaborar, aí que entra uma grande contribuição, a busca para aprender e aperfeiçoar o uso do computador, que é facilitador e ao mesmo tempo complica, quem é aprendiz. (M6)

Através da narrativa digital, consegui desenvolver escrita digital, assim como postar fotos, vídeo; descobri também a existência de site gratuito, assim como aprendi a desbloquear a ideia de que às vezes não somos capazes de fazer algo. Com a narrativa digital tive a oportunidade de refletir sobre situações educacionais. Ou seja, no meu caso abriu um leque educacional abrangendo e aproveitando a tecnologia. (M7)

Esses excertos indicam que no processo de apropriação tecnológica do professor em formação, o sujeito precisa atribuir sentidos à tecnologia para que haja aprendizagem efetiva e posterior recontextualização para a prática pedagógica. Assim, como refere Almeida (2004), "A formação continuada para uso pedagógico do computador inter-relaciona conhecimentos teóricoeducacionais, conhecimentos e habilidades no domínio da tecnologia e atitudes que promovam o desenvolvimento da prática reflexiva" (p. 86). Esses 
três elementos, associados ao olhar para o outro (colega ou aluno) e ao diálogo com suas ideias, aparecem nas aprendizagens referidas pelos mestrandos nos trechos seguintes:

Aprendi a parar e refletir mais a fundo as minhas ações. (M1)

Também reconheço que a leitura das narrativas dos meus colegas me trouxe ideias diferentes, me mostrou a importância da ousadia no preparo de aulas. (M3)

Percebi [com as narrativas] a importância de se registrar por escrito uma dada atividade e, além disso, percebi também a importância de se fazer reflexões com a sala sobre a atividade, pois sempre desenvolvi os trabalhos com a sala e depois finalizava e pronto, nada era refletido e muito menos registrado. (M4)

Os conteúdos trabalhados também foram sendo interpretados de outra forma após escrever sobre ele, acabou sendo uma construção e reconstrução constante favorecendo meu aprendizado. (M10)

Esses elementos foram observados pelos professores-mestrandos quando realizaram suas ações, bem como na leitura das narrativas de outros colegas. Assim, neste item, destacamos que os depoimentos dos mestrandos indicam: a) a aprendizagem sobre o uso da TDIC; b) a aprendizagem de conteúdos curriculares do mestrado mediada pela construção das narrativas digitais; c) a aprendizagem dos mestrandos-professores sobre a própria postura profissional.

\subsection{Potencial das narrativas digitais}

Nossa última macrocategoria trata do "Potencial das narrativas digitais" segundo a percepção dos sujeitos deste estudo. Os excertos anteriores já apresentaram algumas potencialidades por meio das atividades desenvolvidas pelos professores-mestrandos. O depoimento de M3, que ainda não utilizou as narrativas digitais com seus alunos, indica outra possibilidade de uso, como forma de avaliação: "Pretendo usá-las principalmente como forma de avaliar minhas aulas, mas também para que os meus alunos se avaliem e aprendam com as experiências dos colegas" (M3). Nesse depoimento, percebemos que M3 tem uma perspectiva formativa de avaliação, além de perceber o potencial das narrativas digitais como facilitadoras de movimentos de (auto)formação, (eco)formação e 
(hetero)formação (Pineau, 1999), mas também como promotoras de auto e heteroavaliação, enquanto dimensões da avaliação em contextos educativos formais (Pereira, Oliveira, \& Tinoca, 2010).

M3 afirma a intenção de usar as narrativas e uma das formas (para que seus alunos aprendam colaborativamente) está diretamente relacionada à fala anterior da mestranda sobre sua própria aprendizagem com as narrativas: "Também reconheço que a leitura das narrativas dos meus colegas me trouxe ideias diferentes" (M3). Parece-nos que essa inter-relação ilustra o movimento de apropriação feito pela mestranda como aluna e a recontextualização dessa aprendizagem ao seu contexto de trabalho, como professora. A mestranda continua:

Meu próximo passo será pedir que façam suas narrativas, sobre sua trajetória como pequenos cientistas, onde colocarão seus conhecimentos sobre Ciências e como estes conhecimentos contribuíram para (re)significar conceitos sobre Tecnologia, Ambiente e Sociedade. (M3)

Nessa proposição, M3 trata das narrativas de aprendizagem visando promover a ressignificação dos conteúdos curriculares e tomando a narrativa digital como a janela para a mente dos alunos (Almeida \& Valente, 2012).

Apesar de perceberem, ou intuírem (como no caso de M9), o potencial educacional das narrativas digitais, os sujeitos nos apontam para questões curriculares que podem ser impeditivas ou inibidoras do uso desse recurso. $O$ tempo escasso para o cumprimento de todas as atividades curriculares na escola figura como uma dessas questões:

As narrativas digitais são um atrativo para levar os alunos a realizarem registros e quanto mais registrarem, melhores serão. Elas podem levá-los a serem mais criativos, dinâmicos, etc. Penso em um trabalho coletivo dentro da escola ..., mas infelizmente o tempo dentro de sala é curto e precisaria se estender para casa e não são todos que poderão fazer uso delas em casa, pois tenho muitos alunos de baixa renda que não possuem computador ou acesso à internet. (M8)

... não acredito que a narrativa me auxiliou na aprendizagem dessa disciplina. Por conta de tantas coisas que tínhamos que fazer, tantas outras atividades que a professora pedia. ... Talvez, se realmente tivéssemos tempo para refletir sobre as nossas práticas docentes, a narrativa seria um bom caminho. (M9)

Percebi perspectivas ... Porém, eu ainda me considero um pouco fechado em relação a apresentar essa ideia, devido ao tempo super corrido (sic), bem como questões diversas que a política educacional proporciona. (M7) 
Além da escassez de tempo, M7 e M8 ainda destacam dois aspectos: "questões diversas que a política educacional proporciona" e a carência socioeconômica dos alunos. Quanto às questões diversas, podemos inferir que M7 se refere ao currículo prescrito a ser cumprido nas disciplinas específicas (que estratifica e enrijece o trabalho do professor, dificultando-o), à burocracia da escola, e mesmo à dificuldade de acesso e utilização de aparatos tecnológicos nas escolas. Dados da pesquisa TIC Educação realizada pelo CETIC em 2014 (Barbosa, 2015), que ouviu alunos e professores de 1.034 escolas urbanas públicas e privadas de todas as regiões do Brasil, mostram que $80 \%$ dos alunos informaram ter acessado à Internet nos últimos 3 meses por meio de telefone celular, ao passo que $29 \%$ dos alunos (15\% das escolas privadas e $14 \%$ das públicas) afirmaram ter utilizado a Internet em algum estabelecimento de ensino. Tais dados revelam a lacuna existente entre o que ocorre na vida dos alunos e nas escolas, que deixam de explorar o potencial de aprendizagem desses recursos devido a diversos fatores institucionais.

Mesmo considerando o impacto dos empecilhos indicados pelos mestrandos para a utilização das narrativas digitais nas escolas (currículo prescritivo e restrito a uma lista de conteúdos; e dificuldades de uso real das tecnologias), ressaltamos, no final deste item de análise, as principais potencialidades educacionais das narrativas digitais identificadas pelos sujeitos de pesquisa: a) as narrativas digitais podem ser usadas como instrumentos de avaliação; b) as narrativas digitais ajudam a recontextualizar o uso pedagógico das TDIC; c) pelas narrativas digitais é possível maximizar a interface entre conteúdos curriculares e trajetórias pessoais dos estudantes.

\section{Considerações finais}

Iniciamos as reflexões finais deste trabalho investigativo buscando apoio em Bruner (1991) e seu apontamento acerca da Composicionalidade Hermenêutica da narrativa e, mais especificamente em nosso caso, da narrativa digital. Da mesma forma como nós extraímos significados das narrativas expressas pelos mestrandos, o conhecimento partilhado neste texto também será interpretado pelos leitores conforme suas intenções, valores, concepções e significados. Daí a importância de termos tratado neste artigo da trama criada entre o contexto estudado, o enredo da disciplina em 
que ocorreu a produção das narrativas, os fatos e os feitos dos mestrandos num exercício de construção e reconstrução de sentidos que pode servir a outros contextos investigativos e de formação docente.

Nesse sentido, entendemos que este trabalho apresenta resultados e discussões que podem ampliar o espectro teórico já existente sobre a temática das narrativas digitais apontando caminhos para sua aplicação em contextos formais de educação. Além disso, nossos resultados também ratificam a relevância de experiências com narrativas digitais apresentadas em outros estudos sobre contextos de aprendizagem que foram realizados em diversos cursos de pós-graduação (Almeida \& Valente, 2012; Valente \& Almeida, 2014).

O aspecto surpreendente e revelador do presente trabalho é a facilidade com que as experiências realizadas na pós-graduação foram assimiladas e incorporadas às atividades que alguns professores desenvolveram em suas práticas pedagógicas em outros níveis de ensino. Assim, fica patente o potencial formativo do trabalho com narrativas digitais e seus efeitos na reflexão sobre a prática pedagógica e o uso de tecnologias na escola e na ampliação do trabalho docente com uso de TDIC.

A contribuição para a formação dos professores pode ser observada nas categorias identificadas nas respostas dos questionários, como: a) a mudança na prática pedagógica a partir do contato com as narrativas digitais; b) a transformação profissional, uma vez que a mudança na prática pedagógica leva a uma transformação do profissional professor e vice-versa; c) a aprendizagem do professor, descrita pelos mestrandos quanto ao uso da tecnologia, aos conteúdos curriculares da disciplina do mestrado e à própria postura deles em relação à sua atividade profissional; e, finalmente, d) o potencial das narrativas digitais que foi observado e descrito pelos próprios mestrandos.

Esse potencial educativo das narrativas também pode ser observado no fato de elas poderem ser utilizadas nos diferentes níveis de ensino, como a pós-graduação, a graduação e a educação básica, já que muitos dos mestrandos atuam em disciplinas desses níveis de ensino. Outra versatilidade das narrativas digitais, observada neste trabalho e com aplicabilidade em outras situações, é o fato de elas poderem ser utilizadas em diferentes disciplinas, como de formação de professores no Ensino Superior, dos cursos técnicos e do Ensino Fundamental II. 
Assim, os resultados deste estudo contribuem para ampliar nossa compreensão sobre o potencial das narrativas digitais como estratégia de aprendizagem e recurso pedagógico e mostram que esses recursos podem ter um amplo espectro de aplicação na Educação. Além disso, ficou claro pelo estudo que as narrativas digitais podem ser utilizadas em diferentes contextos formativos nos mais diversos níveis de ensino.

Finalmente, salientamos que a elaboração de narrativas digitais permite desenvolver estudos sobre distintas experiências, contextos e conceitos por meio de um processo de representação do pensamento, reflexão, crítica, construção de conhecimento, atribuição de significados e negociação de sentidos entre os participantes.

\section{Referências}

Almeida, M. E. B. (2004). A inclusão digital do professor: Formação e prática pedagógica. São Paulo: Editora Articulação Universidade/Escola.

Almeida, M. E. B., \& Silva, M. G. M. (2011). Currículo, tecnologia e cultura digital: Espaços e tempos do web currículo. Revista e-curriculum, 7(1), 2-19. Disponível em: http://revistas.pucsp.br/index.php/ curriculum/issue/view/397.

Almeida, M. E. B., \& Valente, J. A. (2011). Tecnologias e currículo: Trajetórias convergentes ou divergentes? São Paulo: Paulus.

Almeida, M. E. B., \& Valente, J. A. (2012). Integração currículo e tecnologias e a produção de narrativas digitais. Currículo Sem Fronteiras, 12(3), 57-82. Disponível em: http://www.curriculosemfronteiras.org/vol12iss3articles/ almeida-valente.pdf.

Arroyo, M. G. (2013). Currículo, território em disputa (5 a ed.). Petrópolis/RJ: Vozes.

Bakhtin, M. (1992). Estética da criação verbal. São Paulo: Martins Fontes.

Bakhtin, M. (2009). Marxismo e filosofia da linguagem: Problemas fundamentais do método sociológico da linguagem. São Paulo: Hucitec.

Barbosa, A. (Coord.). (2015). Pesquisa sobre o uso das tecnologias de informação e comunicação nas escolas brasileiras - TIC Educação 2014. São Paulo: Comitê Gestor da Internet no Brasil, Centro de Estudos sobre a Tecnologia da Informação e Comunicação.

Bogdan, R. C., \& Biklen, S. K. (1999). Investigação qualitativa em educação: Uma introdução à teoria e aos métodos. Porto: Editora Porto.

Bottentuit Junior, J. B., Lisbôa, E. S., \& Coutinho, C. P. (2012). Narrativas digitais na formação inicial de professores: Um estudo com alunos de Licenciatura em Pedagogia. Revista Teias, 13(17), 191-204. doi: http://hdl.handle.net/1822/ 20894. 
Bruner, J. (1991). A construção narrativa da realidade. Critical Inquiry, 18(1), 1-21. Disponivel em: https://www.academia.edu/4598706/BRUNER_Jerome. _A_constru\%C3\%A7\%C3\%A3o_narrativa_da_realidade.

Chizzotti, A. (2011). Pesquisa qualitativa em ciências humanas e sociais (4a ed.). São Paulo: Editora Vozes.

Costa, S. R. (2009). Dicionário de gêneros textuais ( $2^{\mathrm{a}}$ ed.). Belo Horizonte: Ed. Autêntica.

Coutinho, C. P. (2010). Storytelling as a strategy for integrating technologies into the curriculum: An empirical study with post-graduate teachers. In C. Maddux, D. Gibson, \& B. Dodge (Eds.), Research highlights in technology and teacher education 2010 (pp. 87-97). Chesapeake, VA: SITE.

Cunha, M. I. (1997). Conta-me agora! As narrativas como alternativas pedagógicas na pesquisa e no ensino. Revista da Faculdade de Educação, 23(1-2). doi:10.1590/S0102-25551997000100010.

Denzin, N. K., \& Lincoln, Y. S. (2006). O planejamento da pesquisa qualitativa: Teorias e abordagens ( $2^{\mathrm{a}}$ ed.). Porto Alegre: Artmed.

Freire, P. (1987). Pedagogia do oprimido (17 $7^{\mathrm{a}}$ ed.). Rio de Janeiro: Paz e Terra.

Galvão, C. (2005). Narrativas em educação. Ciência \& Educação, 11(2), 327-345. http://www.scielo.br/pdf/ciedu/v11n2/12.pdf.

Gatti, B. A. (2010). Formação de professores no Brasil: Características e problemas. Educação \& Sociedade, 31(113), 1355-1379. doi:10.1590/S010173302010000400016.

Gimeno Sacristán, J. (2000). O currículo: Uma reflexão sobre a prática. Porto Alegre: Artmed.

Gonçalves, F. P., \& Fernandes, C. S. (2010). Narrativas acerca da prática de ensino de Química: Um diálogo na formação inicial de professores. Química Nova na Escola, 32(2). Disponível em: http://qnesc.sbq.org.br/online/qnesc32_2/ 10-PE2309.pdf.

Goodson, I. F. (1997). A construção social do currículo. Lisboa: Educa.

INEP (2013). Censo da Educação Básica: 2012 - Resumo técnico. Brasília: Instituto Nacional de Estudos e Pesquisas Educacionais Anísio Teixeira. Disponível em: http://download.inep.gov.br/educacao_basica/censo_escolar/resumos_ tecnicos/resumo_tecnico_censo_educacao_basica_2012.pdf.

Jesus, A. G. (2010). Narrativa digital: Uma abordagem multimodal na aprendizagem de inglês (Dissertação de Mestrado não publicada). Universidade do Minho, Braga. Disponível em: http://repositorium.sdum.uminho.pt/handle/1822/14496.

Larrosa, J. B. (2002). Notas sobre a experiência e o saber da experiência. Revista Brasileira de Educação, 19, 20-28. doi: 10.1590/S1413-24782002000100003.

Passeggi, M. C. (2011). A experiência em formação. Educação, 34(2), 147-156. Disponível em: http://www.redalyc.org/articulo.oa?id=84819058004.

Pereira, A., Oliveira, I., \& Tinoca, L. (2010). A cultura de avaliação: Que dimensões? In F. Costa, G. Miranda, J. Matos, I. Chagas, \& E. Cruz (Eds.), Actas do I Encontro Internacional TIC e Educação: TicEduca (pp. 127-133). Lisboa: Instituto de Educação da Universidade de Lisboa. 
Pineau, G. (1999). A autoformação no decurso da vida: Entre a hetero e ecoformação. In P. Carré \& P. Gaspar (Orgs.), Tratado das ciências e das técnicas de formação (pp. 327-348). Porto Alegre: Instituto Piaget.

Robin, B. R. (2008). Digital storytelling: A powerful technology tool for the 21st century classroom. Theory Into Practice, 47(3), 220-228.

Santaella, L. (2007). Linguagens líquidas na era da modernidade. São Paulo: Paulus.

Valente, J. A., \& Almeida, M. E. B. (2014). Narrativas digitais e o estudo de contextos de aprendizagem. EmRede: Revista de Educação a Distância, 1(1), 32-50. Disponível em: http://www.aunirede.org.br/revista/index.php/emrede/article/ view/10.

Vieira Pinto, A. (2005). O conceito de tecnologia (vol. 1). Rio de Janeiro: Contraponto.

Vygotsky, L. S. (1989). Formação social da mente. São Paulo: Martins Fontes.

Vygotsky, L. S. (2000). A construção do pensamento e da linguagem. São Paulo: Martins Fontes. 


\title{
CURRICULUM, DIGITAL NARRATIVES AND TEACHER TRAINING: FROM GRADUATE TO SCHOOL EXPERIENCES
}

\begin{abstract}
Training teachers to integrate technology into the curriculum in different educational contexts was the focus of this study, which aimed to understand how the development of digital narratives contributed to this training. Educators investigated were master's students of a Graduate Program in Science Teaching at a Brazilian public university and were also classroom teachers in various educational levels. The learning strategy was based on the development of digital narratives. The data in this research were collected through an electronic questionnaire administered to the subjects. The results indicate: a) changes in the way the graduate students came to understand the pedagogical practice that they developed; b) learning related to the production of digital narratives and its recontextualized application in different subjects taught by the students; c) perception, by the subject, of the digital narratives' educational potential.
\end{abstract}

Keywords

Educational technologies; Learning; Teaching practice; Science education

\section{CURRÍCULO, NARRATIVAS DIGITALES Y FORMACIÓN DE PROFESORES: EXPERIENCIAS DEL POSTGRADO A LA ESCUELA}

\section{Resumen}

La formación de educadores para la integración de las tecnologías al currículo en diferentes contextos educativos fue el enfoque de este estudio cuyo objetivo era entender de qué manera el desarrollo de las narrativas digitales aportó para esa formación. Los educadores estudiados cursaban la Maestría de un Programa de Postgrado en Enseñanza de Ciencias de una universidad pública brasileña y también actuaban como profesores en diversos niveles de 
enseñanza. La estrategia de aprendizaje se basó en el desarrollo de narrativas digitales. Los datos de esta investigación fueron recopilados por medio de un cuestionario electrónico aplicado a los sujetos. Los resultados del estudio indican: a) cambios en la manera en que los estudiantes de maestría pasaron a entender la práctica pedagógica que desarrollan; b) aprendizajes relacionados a la producción de narrativas digitales y con su aplicación recontextualizada en diferentes disciplinas impartidas por los alumnos de la Maestría; c) percepción, por los sujetos, del potencial educativo de las narrativas digitales.

Palabras-clave

Tecnologías educativas; Aprendizaje; Práctica pedagógica; Enseñanza de Ciencias

Recebido em março/2016 Aceite para publicação em setembro/2016

i Programa de Educação: Currículo, Pontifícia Universidade Católica de São Paulo e Universidade Federal de Itajubá, Brasil.

ii Programa de Pós-Graduação em Educação: Currículo e Grupo de Pesquisa Formação de educadores com Suporte em Meio Digital, Pontifícia Universidade Católica de São Paulo, Brasil.

iii Departamento de Multimeios, Mídia e Comunicação, Núcleo de Informática Aplicada à Educação (NIED), Universidade Estadual de Campinas, Brasil.

Toda a correspondência relativa a este artigo deve ser enviada para: Alessandra Rodrigues, Universidade Federal de Itajubá, Instituto de Física e Química/Centro de Educação, Av. BPS, 1303, Bairro Pinheirinho, Itajubá - MG, Brasil. E-mail: alessandrarodrigues@unifei.edu.br 